\title{
A pontuação e sua metalinguagem gramatical
}

\author{
Véronique Dahlet \\ Universidade de São Paulo
}

\section{Résumé}

En s'appuyant sur le chapitre Ponctuation de cinq grammaires normatives et descriptives de langue portugaise, cette contribution analyse les présupposés et la méthodologie, dont on verra qu'ils déterminent leur métalangage. Parmi les présupposés, le plus contestable mais aussi le plus récurrent à donner à la ponctuation une dimension oralisante, ce qui entraine une série d'erreurs épistémologiques. Quant à la méthodologie adoptée, elle se caractérise par une grande hétérogénéité des critères de description et débouche ainsi sur une incohérence structurelle. 


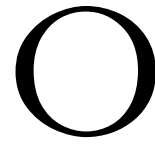

s manuais de gramática servem para adquirir modelos normativos, condição para escrever bem e para reproduzir esses modelos a cada vez que se trata de utilizar a língua escrita. Ora, nesta proposta do bem escrever, a pontuação exerce um papel constante. No entanto, a análise do funcionamento interno do discurso gramatical - metalinguagem e metodologia -, mostrará que as gramáticas ajudam muito pouco em matéria de saber pontuar. Não se trata, evidentemente, de colocá-las em questão em bloco, pois elas continuam sendo um instrumento de referência constante no habitus escolar (e universitário, no caso dos cursos de Letras), mas ainda assim é possível, mesmo adotando o espírito das gramáticas, racionalizar, reorientar e, enfim, sistematizar a noção e o domínio da pontuação. ${ }^{1}$

\section{DA METALINGUAGEM: COMO INTRODUÇÃO, FAÇAMOS A PAUSA}

O conjunto das cinco gramáticas consultadas abre o capítulo Pontuação com uma apresentação geral de sua função. ${ }^{2}$ Todas evocam de início a noção de pausa, dada como central. Essa noção, sistematicamente empregada, invariavelmente considerada, tanto em diacronia como em sincronia, é, no entanto, uma das mais imprecisas. Se a pausa se justifica historicamente, na medida em que, quando a leitura era feita em voz alta, era de fato necessário parar para retomar a respiração, ${ }^{3}$ ela deveria ser seriamente reconsiderada, já que uma série de trabalhos sobre a leitura demonstrou que ela é hoje visual. Os sinais de pontuação são sinais vi-lisíveis captados pelo olho; a escrita é antes de mais nada um espaço gráfico bidimensional e não 
pode ser confundido com o oral, seja no nível das unidades distintivas - fonemas vs grafemas - seja no nível dos marcadores sintáticoenunciativos - prosodemas vs topogramas - (ANIS, 1988, p. 145). ${ }^{4}$ Ora, as gramáticas associam abusivamente a pontuação ao oral, como se o deslizamento fosse óbvio. Assim, pois, no que diz respeito à pausa, que, desligada de qualquer definição, se refere ora ao escritor (lado produção) ora ao leitor (lado recepção), TORRES (s/d., p. 254) diz que a pontuação serve "para indicar na escrita as diferentes pausas que devem ser observadas por quem fala ou lê" (grifo meu); KURY (1988), BARROS (1985) e CUNHA (1980) vêem na pontuação um meio, ainda que muito imperfeito, de compensar as perdas que a passagem do oral ao escrito produz. ${ }^{5}$ É nesse sentido que os sinais tentam "reproduzir as pausas, as cadências, o ritmo, a entoação da linguagem falada" (KURY, 1988, p. 65); que eles "procuram suprir esta carência, ou melhor, reconstituir aproximadamente o movimento vivo da elocução oral" (CUNHA, 1980, p. 420) (grifo meu). Quaisquer que sejam as paráfrases, elas todas mantêm uma concepção da escrita como uma forma fraca e desviada do oral. Essa visão, no final das contas desvalorizante da escrita, não motiva necessariamente os alunos a dominar esse código, cuja importância na construção social da imagem de si, no entanto, conhecemos. Mas o que é mais grave é o impasse total da tomada em consideração das especificidades da escrita nas quais a pontuação encontra seu lugar, porque ela constitui um obstáculo importante para a aquisição da escrita: é de fato muito mais difícil apropriar-se de uma tecnologia, quando a representação que se faz dela é errônea. É muito mais difícil, por exemplo, produzir uma estruturação satisfatória no nível intra- e inter-frástico quando supomos que a pontuação se esforça para reproduzir as inflexões, o ritmo e inclusive a cadência do oral. Assim, existe uma grande probabilidade de que o aluno corra o risco de tomar o oral como modelo da escrita. Ora, a exemplificação da norma não pode substituir a explicitação das especificidades da escrita, por mais simplificada que ela seja.

Vemos então que o conjunto das gramáticas apresenta, em sua introdução à pontuação, um duplo engano epistemológico: inicial- 
mente, com relação à escrita, cujo código é apresentado com se fosse obviamente totalmente tributário do oral, mas também com relação à leitura/escritura, em relação às quais se pressupõe que coloquem em jogo a totalidade do aparelho fisiológico da voz e segundo as mesmas modalidades que na linguagem falada.

\section{QUESTÕES DE METODOLOGIA}

Vou me limitar aqui a assinalar os procedimentos metodológicos mais problemáticos na perspectiva da aprendizagem do escrito. A análise do caso da vírgula, da relação entre pontuação e pensamento, e, enfim, da pontuação na produção/recepção segundo os tipos de escrita fará sobressair uma heterogeneidade quase generalizada dos critérios.

\subsection{O caso da vírgula: "para indicar" ou "para separar"?}

Vimos que, na introdução geral à pontuação, as gramáticas se servem da noção vaga de pausa, atribuindo-lhe uma função vocal. Essa mesma representação é retomada no começo das rubricas: "A vírgula assinala pausa ligeira, com o tom da voz geralmente em suspenso" (KURY, 1988, p. 65); "A vírgula marca uma pausa de pequena duração" (CUNHA, 1980, p. 421); "A vírgula indica a pausa mais fraca” (ALI, 1969, p. 228). Entretanto, assim que os autores começam a exemplificar os empregos desse sinal, o registro passa bruscamente para considerações gramaticais: "Entre os termos de uma oração, separa quaisquer termos assindéticos de uma função sintática composta" (KURY, 1988, p. 65). É inútil multiplicar as citações recheadas de designações gramaticais que, de um manual a outro, se entrecruzam: todas apresentam de forma patente essa ruptura de registro. Qual é a articulação funcional entre "para indicar a pausa mais fraca" e, por exemplo, "para separar os termos coordenados que se mencionam seguidamente sem auxílio de conjunção" (ALI, 1969, p. 228)? Em outras palavras, a pausa, que até 
então sempre teve como referência a linguagem oral, teria igualmente uma função sintática? Ou será que a pausa remeteria a dois domínios distintos, porém simultâneos, a saber, ao oral e à sintaxe da escrita?

\subsection{Descrição gramatical e pensamento}

Notamos uma outra mistura de registros, que alterna no mesmo impulso a descrição gramatical e a explicação de uma prática pelo recurso ao movimento do pensamento. Assim, lemos sobre a vírgula: "Antes da partícula ou, denotando alternativa ou retificação do pensamento" (ALI, 1969, p. 229). Esse tipo de explicação é sistemática para as reticências (doravante, [...]): "interrupção do pensamento ou hesitação em exprimi-lo" (Id.); "para indicar que a idéia que se pretende exprimir não se completa" (CUNHA, 1980, p. 432); "deixa o pensamento em suspenso" (KURY, 1988, p. 76). Ora, mais uma vez, a evocação do movimento do pensamento se fundamenta sobre um estreito paralelismo entre o oral e o escrito, que pode ser assim formulado: quando no oral há hesitação, esquecimento, alusão, implícito, etc., isso se traduz pela interrupção momentânea ou definitiva da cadeia falada; conseqüentemente, no escrito, os mesmos casos se traduzem pelas [...]. Reencontramos o fato de não levar em conta as diferenças irredutíveis entre os dois códigos. Contrariamente ao oral, que é uma comunicação in situ, o escrito, é preciso lembrar, é uma comunicação deslocada no tempo: é exatamente por isso que o escritor pode a qualquer momento, sempre que quiser, voltar atrás, corrigir-se, apagar, transformar, sem que nada apareça na versão final que seu destinatário lerá. Além do fato de que os recursos cognitivos diferem de um código ao outro, as [...] mostram com clareza, porque a comunicação não é instantânea, que se trata de uma encenação, da construção de um puro artefato que busca provocar uma reação do leitor, e não de uma tradução dos movimentos do pensamento ou de estados psicológicos. O mesmo se pode dizer do [!] e freqüentemente do [?]. 


\subsection{Pontuação, em produção/recepção e textos de especialidade}

Eu gostaria agora de mostrar duas outras misturas de registros. A primeira diz respeito aos sinais, que seria pertinente distinguir segundo eles se situem em produção ou em recepção; a segunda mistura de registros remete à variedade de tipos de textos.

a) No conjunto do corpus, notaremos uma ausência de discriminação entre pontuação manuscrita e pontuação em textos impressos, sendo as duas colocadas no mesmo plano em termos de importância, de freqüência (e de interesse para o aprendiz da escrita). Ora, o aluno escreve ainda maciçamente à mão: essa colocação no mesmo nível de pontuações diferentes não corresponde à sua realidade redacional. Assim, encontramos, ao lado dos sinais usuais, "o asterisco" [*], o parágrafo [§] e os colchetes [ [ ] ]" (TORRES, s.d., p. 260). Se é verdade que o aluno será sempre mais levado a redigir no computador, esses sinais permanecem ainda, para a maioria, confinados à recepção, de um lado, e de outro, são sinais próprios para a publicação, isto é, a uma convenção de apresentação, estranhamente classificados como sinais melódicos. ${ }^{6}$ Conviria, por conseguinte, apresentá-los como tais. Por exemplo, os [ [ ] ] são apresentados, em Barros e em Cunha, de maneira singularmente restritiva, como sendo "de largo uso na Lingüística, colocando em relevo a palavra fonológica” (BARROS, 1985, p. 75); Torres associa o [\$] aos textos legais, enquanto Cunha associa aos textos de lei o [;]. Em suma, se houvesse uma preocupação com coerência, as gramáticas deveriam levar em conta o itálico, o negrito e a letra de forma, com os quais o aluno está em contato permanente (jornais, publicidade, histórias em quadrinhos) e que pode vir a utilizar se dispõe de um computador.

b) Essa observação sobre as pontuações de textos de especialidade está ligada à indiferenciação: são colocados lado a lado, além das menções a textos de lei ou de Lingüística, o gênero epistolar (a vírgula serve para separar o lugar da data - menção assinalada em todas as gramáticas consultadas), as indicações bibliográficas e 
cenográficas (os [( )] em CUNHA, 1980, p. 435), ou ainda, os provérbios (a vírgula "para separar as frases proverbiais", em TORRES, s.d., p. 256). Os casos que ilustram melhor essa mistura são o travessão e as [...].

Para me limitar apenas ao travessão, todas as gramáticas colocam na mesma rubrica o travessão de diálogo e o travessão duplo; mas, de fato, o travessão de diálogo dá conta de uma situação dialogal, específica ao gênero literário, que implica automaticamente a representação em uma forma convencional do diálogo representado, ao passo que o travessão duplo permite inserir um subenunciado no enunciado receptor.

\section{PROPOSTAS}

\subsection{Os sinais de pontuação: sinais vi-lisíveis}

Creio que todos concordarão que é difícil, quem sabe impossível, pretender a compreensão de um sistema, qualquer que seja ele, sem defini-lo, bem como a área que ele afeta. Para isso, seria preciso:

a) Afastar-se do fonografismo, para reintegrar claramente a pontuação em sua área, que é a escrita. Definimos a escrita como um continuum escritural que se manifesta num espaço gráfico bidimensional, ou seja, de dimensão horizontal (linear) e vertical (hierarquizante). Esse esclarecimento inicial, que está ao alcance de qualquer aluno, mesmo muito jovem, é um pré-requisito à entrada no mundo da escrita. A partir da sensibilização para a bidimensionalidade, o papel da pontuação poderá aparecer de maneira operacional como um sistema (e não mais como uma enumeração de regras prescritivas), que se compõe de duas vertentes: a pontuação sintática e a pontuação enunciativa. Voltaremos a essa questão adiante (cf. 3.2).

b) Definir a função global da pontuação e distinguir preliminarmente os níveis que ela afeta. Defini-la, por exemplo, como um "conjunto 
de sinais visuais de organização e de apresentação da escrita que acompanham o texto escrito" (CATACH, 1980, p. 21) parece-me um ponto de partida satisfatório, pois toda a ênfase está colocada em primeiro lugar na noção de construção que remete à regulação sintático-semântica, e, em segundo lugar, na noção de apresentação, lembrando assim o fato de que a escrita é acompanhada também de uma forma, que faz (e produz) sentido. Mas isto não basta: conviria em seguida distinguir os três níveis de pontuação: pontuação de palavra, que remete à ortografia; pontuação de frase (nível intrafrástico e frástico); e pontuação de texto (nível interfrástico). Bueno acrescenta à pontuação de frase a pontuação de palavra (hífen), e mesmo o trema, que é estranho à pontuação, já que é um sinal diacrítico; Ali e Torres colocam junto pontuação de frase e de texto [§]. Isso mostra a variedade dos corpora. Mas não seria nada incômodo (com a condição, é lógico, de não introduzir elementos heterogêneos) se as gramáticas indicassem explicitamente suas posições respectivas.

No estado atual das coisas, a ausência de reflexão teórica sobre a pontuação bloqueia toda possibilidade de dar conta desta dimensão gráfica, essencial para uma boa performance escrita, pois é precisamente nesse capítulo que as gramáticas podem tomar posição em relação à escrita. Mas daí decorrem igualmente metodologias aproximativas, cujos procedimentos vagos e confusos (cf. supra), longe de permitir ao aluno um domínio razoável, o mantêm, no melhor dos casos, num comportamento de imitação.

\subsection{Pensar a pontuação enquanto sistema}

Não é utópico imaginar que as gramáticas qualificadas como normativas, descritivas, fundamentais ou modernas se dêem como tarefa uma racionalização do dispositivo descritivo-normativo da pontuação. Podemos, com efeito, classificar os sinais em dois conjuntos principais, fundados em sua função. ${ }^{7}$ 


\subsubsection{Primeira classe: [alínea] [.] [i] [:] []].}

Esses sinais figuram na mesma classe, na medida em que têm a função comum de segmentar o continuum escritural. Eles delimitam os sintagmas, separando-os, e os hierarquizam, indicando a natureza de sua relação. A ordem na qual aparece essa classe de sinais não é aleatória: ela remete a sua força de segmentação. Percebe-se de imediato a validade operatória dessa metodologia (baseada, repito, numa teoria da escrita), que substitui a prescrição normativa por operações sintáticas, o que tem como correlato uma organização coerente dos exemplos-ocorrências, ausente das gramáticas. Em suma, tratar-se-ia de demonstrar as condições de atualização do sinal, em vez de designar, sob a forma de acumulação, as categorias gramaticais dos segmentos afetados por esse sinal.

Ilustrarei meu propósito através da maneira pela qual CUNHA (1980, p. 421-423) apresenta algumas das regras relativas à [,]. Vejamos inicialmente três exemplos-ocorrências e, a seguir, as classificações e comentários correspondentes.

\begin{tabular}{|l|l|}
\hline $\begin{array}{l}\text { "Eu, você, suas irmãs, o Trindade, } \\
\text { nossos amigos, deveríamos ser } \\
\text { lacrados todos dentro do Solar. } \\
\text { (G. FRANÇA DA LIMA) }\end{array}$ & $\begin{array}{l}\text { - I. No interior da oração } \\
\text { serve: } 1^{\circ} \text { ) Para separar elementos que } \\
\text { exercem a mesma função sintática } \\
\text { (sujeito composto, complementos, } \\
\text { adjuntos), quando não vêm unidos } \\
\text { pelas conjunções } e \text {, ou e nem. }\end{array}$ \\
\hline $\begin{array}{l}\text { Ficou branquinha, branquinha, } \\
\text { Com os desgostos humanos. }\end{array}$ & $\begin{array}{l}2^{\text {o }} \text { ) Para separar elementos que } \\
\text { exercem funções sintáticas diversas, } \\
\text { geralmente com a finalidade de } \\
\text { realçá-los. } \\
\text { d) para isolar os elementos pleonás- } \\
\text { ticos ou repetidos. }\end{array}$ \\
\hline $\begin{array}{l}\text { Levantava-me, passeava, tamborilava } \\
\text { nos vidros das janelas, assobiava. } \\
\text { (M. de ASSIS) }\end{array}$ & $\begin{array}{l}\text { - II. Entre orações, emprega-se a } \\
\text { VÍRGULA: }\end{array}$ \\
\hline
\end{tabular}


As condições que pedem a vírgula são rigorosamente idênticas nos exemplos-ocorrências: trata-se de elementos sintaticamente equivalentes que, para construir exatamente esta equivalência, são segmentados, limitados pela [,]. Tal é a lógica operatória em ação nessas ocorrências. Ela subsume as especificações gramaticais (cf. coluna da direita) cujas ilustrações através de exemplos são apenas realizações potenciais. De fato, expor antes dos exemplos-ocorrências categorizações gramaticais é um vício de forma que toma a causa pela conseqüência, e vice-versa. As gramáticas começam, de fato, com o inventário das categorizações gramaticais (elas não passam, de fato, de simples designações ${ }^{8}$ ) como se fossem estas (apresentadas como causa) que comandassem tal sinal de pontuação (apresentado como conseqüência), enquanto que é tal resolução sintática (causa) que comanda tal segmentação, que por sua vez recebe na gramática tal designação.

\subsubsection{Segunda classe: os sinais enunciativos}

Os sinais enunciativos, ${ }^{9}$ assim qualificados porque participam na organização do jogo enunciativo, seja ele plurivocal ou univocal, compreendem:

a) as marcas do discurso citado: [“"], [itálico] ${ }^{10}$, [travessão de diálogo];

b) os marcadores expressivos: [letra de forma], [sublinhado], [itálico], [travessão];

c) os hierarquizadores discursivos: [:], [- -], [( )];

d) os marcadores de modalidade enunciativa: [?], [!], [...].

Eu me limitarei aqui a duas breves observações. De fato, parece-me indispensável:

a) distinguir claramente, para as marcas de discurso citado, as representações formais de diálogo (situação plurivocal em contexto literário ou similar: voz do narrador e de pelo menos duas personagens; transcrição de entrevista), na medida em que 
os sinais são a resultante de convenções que os impressores editores elaboraram progressivamente a partir do séc. XVI. É o caso do travessão de diálogo e das [...], a respeito dos quais se estabeleceu que, por legítimos motivos de racionalização do sistema editorial, eles significariam a interrupção do discurso do locutor 1 pelo locutor 2 .

b) considerar os sinais de modalidade enunciativa ( [?], [!], [...]) como escolhas de postura enunciativa que, em todos os casos e por razões pragmáticas fortemente dependentes do tipo de texto, procuram agir sobre o destinatário. Também neste caso, isso evitaria, por exemplo, a enumeração inoperante de estados de alma que se imagina que sejam os do enunciador, de tal modo que [!] indica sentimentos como "surpresa, admiração, espanto, piedade, súplica, medo"; realçar-se-iam estratégias de ação sobre o destinatário que, qualquer que seja o caso, o enunciador não tem diante de si.

Esses são, então, os pontos de "disfuncionamento" do discurso gramatical que me pareceram mais importante destacar. A tomada de posição conceitual que abre o capítulo sobre a pontuação determina, de fato, o desenvolvimento posterior da apresentação, mesmo que seja fortemente normativa. Ora, submeter previamente a pontuação a uma dependência estreita do oral leva quase inevitavelmente a aporias, a representações aproximativas, bem como a uma metodologia confusa. É em função desse breve acerto que se organizaram algumas sugestões que fiz. Essa análise, incompleta e talvez muito rápida, terá entretanto demonstrado, espero, o benefício metodológico que se obtém apresentando os sinais de pontuação à luz das condições funcionais que os presidem. Mas o benefício é também um benefício cognitivo para o aluno, pois se pode esperar que esse acerto teórico e metodológico o ajudará a dotar-se não somente de conhecimentos fatuais ("sei que"), mas também procedurais ("sei como") indispensáveis para uma entrada satisfatória na escrita, cuja importância crucial no processo de reconhecimento social e institucional não precisa mais ser demonstrado. 


\section{NOTAS}

* Assessoria da versão em português: Sírio Possenti (UNICAMP).

${ }^{1}$ De fato, não se trata de mover um processo contra as gramáticas. Sabe-se que o último nível de análise gramatical é a frase, e isso restringe necessariamente seu campo.

${ }^{2}$ ALI, 1969; BARROS, 1985; BUENO, 1958; CUNHA, 1980; KURY, 1988; TORRES, [s.d.].

3 Bueno é o gramático mais explícito sobre este ponto: "Respiração - Quem necessita de maiores e mais freqüentes pausas para respirar, certamente, empregará maior número de vírgulas. Quem possuir bons pulmões e puder conter o fôlego por mais tempo, dispensará numerosas pausas" (BUENO, 1958, p. 458). Se usarmos a mesma lógica, temos então o direito de nos perguntar se o leitor deve observar as mesmas pausas que o escritor, independentemente de suas próprias capacidades pulmonares.

${ }^{4}$ Colocando a análise da escrita na perspectiva autonomista, Anis distingue três tipos de grafemas: os grafemas alfabéticos, ou alfagramas, que são unidades distintivas; grafemas pontuativo-tipográficos, ou topogramas, que são indicadores sintáticos e enunciativos, e, enfim, grafemas logogramáticos, ou logogramas, que remetem a grafemas únicos, que correspondem a uma unidade significativa, como, por exemplo, \&,\$ (ANIS, 1988, p. 150-156 e Glossário).

${ }^{5}$ A imagem do travestimento ou do desnaturamento que a escrita suscita através dos séculos, de Platão a Lévi-Strauss, não deveria envolver gramáticos ou lingüistas no mesmo paradigma persistente da perda. Assim, se refletirmos um momento no que significa: compensar as perdas que a passagem do oral ao escrito produz, isso implica, literalmente, que se pressupõe que não haja escrita que não tenha uma versão primeira, original, isto é, oral.

${ }^{6}$ De resto, o asterisco não é, propriamente dito, um sinal de pontuação, nem tampouco as [\{ \}]. Quanto aos [ [ ] ], estão em vias de cair, por assim dizer, no domínio público, sob o efeito da microedição que se generalizou há uns vinte anos.

${ }^{7}$ Estou me apoiando na classificação proposta por ANIS (1988, p. 122-138).

${ }^{8}$ Designar não é explicar o funcionamento: é um ato de identificação e não uma apresentação de operação. Assim sendo, a gramática só se dirige de fato a um público já formado, na medida em que, com a ajuda da experiência, terá interiorizado intuitivamente as operações.

${ }^{9}$ De predominância enunciativa, pois é claro que a função segmentadora continua a se exercer. Anis os qualifica de polifônicos.

${ }^{10}$ Nesse caso, o sublinhado é para o manuscrito o que o itálico é para o impresso. 


\section{REFERÊNCIAS BIBLIOGRÁFICAS}

ALI, Said. Gramática secundária da língua portuguesa. São Paulo: Melhoramentos, 1969.

ANIS, Jacques. L'écriture. Théories et descriptions. Bruxelles: De Boeck-Université, 1988. (Coll. Prismes problématiques, 10)

BARROS, Enéas Martins de. Nova gramática da lingua portuguesa. São Paulo: Atlas, 1985.

BUENO, Fransisco da Silveira. Gramática normativa da língua portuguesa: curso superior. São Paulo: Saraiva, 1958.

CATACH, Nina. La ponctuation. Langue Française, Paris: Larousse, n. 45, février 1980.

CUNHA, Celso. Gramática do português contemporâneo. Rio de Janeiro: Livraria Editora, 1980.

KURY, Adriano da Gama. Ortografia, pontuação, crase. 2. ed. Rio de Janeiro: FAE, 1988.

TORRES, A. Moderna gramática expositiva. Rio de Janeiro: Fundo de Cultura, [s.d.]. 